\title{
La protección de los derechos fundamentales frente a particulares
}

\author{
Diego Valadés \\ Director del Instituto de Investigaciones Jurídicas \\ de la UNAM, miembro del Sistema Nacional \\ de Investigadores, de la Academia Mexicana de la Lengua \\ y de El Colegio de Sinaloa.
}

SUMARIO: 1. CONSIDERACIONES PRELIMINARES.- 2. UN PROYECTO DE REFORMAS.- 3. ANTECEDENTES EUROPEOS.- 4. ANTECEDENTES ASIÁticos.-5. ANTECEDENTES AMERICANOS.-6. ConsiDERACIONES FINALES.

\section{CONSIDERACIONES PRELIMINARES}

Las últimas décadas del siglo XX correspondieron a un paulatino desmantelamiento del tamaño del Estado. Este fue un fenómeno generalizado en el mundo. La tesis del Estado pequeño no es nueva, pero su implantación y efectos sí lo son"1. De manera paralela a ese "empequeñeci-

1 En 1767 P. S. DU PonT DE Nemours publicó los trabajos de Quesnay bajo el título La Physiocratie; ou, constitution naturelle du gouvernement le plus avantageux au genre humain, reduciendo la actividad del Estado a la protección de la vida y de la propiedad, a la realización de obras públicas y al desarrollo de la educación; en 1884 HeRBERT SPENCER, The Man versus the State, formuló un sólido argumento individualista contra el Estado, considerándolo un obstáculo para la industria de los particulares; en 1931 ANTONIO ZozAYA, La sociedad contra el Estado, planteó el problema de la inmoralidad del Estado; en 1974 Robert Nozick, Anarchy, State an Utopia, postuló la necesidad del "Estado mínimo"; en 1979 FRIEDRICH A. HAYEK, Law, legislation and liberty, aportó una amplia gama de consideraciones en contra del Estado intervencionista; en 1985 James M. Buchanan y Geoffrey Brennan, The reason of rules. Constitutional political economy, subrayaron que existe "una vuelta al escepticismo sobre la política y el gobierno que caracterizaron al siglo XVIII que hará que 
miento" del Estado, corre su correlato: el fortalecimiento del Estado intangible, entendido como los entes de derecho privado que ejercen funciones de naturaleza pública. Además, el poder de las personas físicas y de las corporaciones se deja sentir en cuanto a las relaciones con los particulares que se encuentran en situación de desventaja. El Estado representó una amenaza real para la libertad y la autonomía de las personas; pero hoy los individuos se encuentran expuestos a un fuego doble: el del Estado y el de otros particulares. El poder de éstos se ha dilatado casi en la proporción en que las potestades públicas han disminuido.

A manera de ejemplo, en diferentes países y en distintos momentos (aunque todos relativamente recientes) se han planteado casos tales como los siguientes: sujetar la contratación de trabajadores a su renuncia expresa al derecho de sindicación; exclusión de la prestación de servicios (alojamiento, alimentación, educación) o de la participación en actividades (religiosas, políticas, sociales), por razones de raza, sexo, u otros motivos que igualmente entrañan discriminación; obligar a las mujeres a mantenerse célibes o infecundas, como condición para preservar un empleo. Casos como estos, y otros muchos más, han venido siendo vistos por los tribunales.

Paulatinamente se va generalizando entre los jueces la certidumbre de que los derechos fundamentales, tradicionalmente expuestos ante el poder arbitrario del Estado, también lo están ante la acción no controlada de los particulares. En este estudio se presentarán diversos ejemplos para ilustrar esa tendencia.

nuestra atención se concentre sobre las reglas y limitaciones de los gobiernos"; en 1987 Michel Crozier, Etat modest, Etat moderne. Stratégies pour un autre changement, abogó por un "Estado modesto, respetuoso de los ciudadanos al servicio de los cuales acepta actuar"; y en 1993 RICHARD A. EPSTEIN, Bargaining with the government, desarrolló con amplitud los términos de la relación entre el poder y los individuos, sobre la base de la autonomía individual como contrapunto del poder estatal. 


\section{UN PROYECTO DE REFORMAS}

El proyecto de Ley de Amparo de la Suprema Corte de Justicia de México presentado en 2001 propone cambios de gran calado; en cuanto al concepto de autoridad responsable.

Véase la propuesta de ese tribunal constitucional:

\begin{tabular}{|l|l|}
\hline \multicolumn{1}{|c|}{ Texto vigente } & \multicolumn{1}{c|}{ Texto propuesto } \\
\hline $\begin{array}{l}\text { Artículo 103. Los tribunales de la } \\
\text { Federación resolverán toda } \\
\text { controversia que se suscribe: }\end{array}$ & $\begin{array}{l}\text { Artículo 103. Los tribunales de la } \\
\text { Federación resolverán toda } \\
\text { controversia que se suscite por } \\
\text { normas generales o actos de } \\
\text { autoridad que violen las } \\
\text { garantías que consagra esta } \\
\text { I. Ponstitución o los derechos } \\
\text { autoridad que viole las } \\
\text { garantías individuales; } \\
\text { humanos que protegen los }\end{array}$ \\
II. $\begin{array}{l}\text { Por leyes o actos de la } \\
\text { autoridad federal que vulneren } \\
\text { o restrinjan la soberanía de los } \\
\text { Estados o la esfera de } \\
\text { competencia del Distrito }\end{array}$ & $\begin{array}{l}\text { generales en la materionales que estén } \\
\text { de acuerdo con la propia } \\
\text { Federal, y }\end{array}$ \\
$\begin{array}{l}\text { Constitución, celebrados y que se } \\
\text { celebren por el Presidente de la } \\
\text { República, con aprobación del } \\
\text { III. Por leyes o actos de las } \\
\text { autoridades de los Estados o } \\
\text { del Distrito Federal que } \\
\text { invadan la esfera de } \\
\text { competencia de la autoridad } \\
\text { federal. }\end{array}$ & Senado ${ }^{2}$. \\
\hline
\end{tabular}

Como se puede advertir, el proyecto, con una sutil supresión del artículo determinado "la", aplicado a los actos con relación a los cuales se protege a las personas, prepara un giro copernicano en el sistema de protección de los derechos fundamentales. La estructura actual del artículo 103 está directamente referida a la autoridad pública. La fracción primera alude a "leyes o actos de la autoridad", donde la preposición disyuntiva "o" no deja lugar a dudas

2 El proyecto de 2000 decía: "Los tribunales de la Federación resolverán toda controversia que se suscite por normas generales o actos de autoridad que violen las garantías que consagra esta Constitución o los derechos humanos que protegen los tratados internacionales generales en la materia". 
de que se alude de un órgano del poder, lo que se reafirma en las dos siguientes fracciones.

El cambio propuesto preludia un nuevo concepto de autoridad responsable en la Ley de Amparo:

\begin{tabular}{|c|c|}
\hline Texto vigente & Texto propuesto \\
\hline $\begin{array}{l}\text { Artículo } 11 . \text { Es autoridad } \\
\text { responsable la que dicta, } \\
\text { promulga, publicca, ordena, } \\
\text { ejecuta o trata de ejecutar la } \\
\text { ley o el acto reclamado. }\end{array}$ & $\begin{array}{l}\text { Artículo } 4^{\circ} \text {. Son parte en el juicio de } \\
\text { amparo: } \\
\text { I. } \\
\text { II. La autoridad responsable, } \\
\text { teniendo tal carácter, con } \\
\text { independencia de su naturaleza } \\
\text { formal, la que dicta, ordena, ejecuta } \\
\text { o trata de ejecutar el acto que crea, } \\
\text { modifica o extingue situaciones } \\
\text { jurídicas en forma unilateral y } \\
\text { obligatoria ; u omita el acto que de } \\
\text { realizarse crearía, modificaría o } \\
\text { extinguiría dichas situaciones jurídicas }{ }^{3} \text {. }\end{array}$ \\
\hline
\end{tabular}

El propuesto es un concepto enteramente nuevo, como subraya uno de sus autores, el maestro Héctor Fix-Zamudio ${ }^{4}$. Para el maestro Fix, además, debería hablarse, con mayor propiedad, de "autoridad demandada", pues la responsabilidad sólo se determina con la sentencia ${ }^{5}$. En este, como en muchos otros temas, el maestro ha sido precursor. En 1984 argumentó ampliamente acerca de la necesidad de modificar el concepto de autoridad responsable: "Se sigue utilizando, al menos en la legislación y la jurisprudencia de nuestro país, un concepto superado de autoridad,

${ }^{3}$ El proyecto de 2000 decía: "Artículo 4º. Son parte en el juicio de amparo:

I. ...

II. La autoridad responsable, teniendo tal carácter la que dicta, ordena, ejecuta o trata de ejecutar $\mathrm{u}$ omite el acto que crea, modifica o extingue situaciones jurídicas en forma unilateral y obligatoria;".

${ }^{4}$ Los otros distinguidos integrantes de la comisión designada por la Suprema Corte de Justicia de la Nación para formular el proyecto fueron: Humberto Román Palacios, quien la presidió, Juan N. Silva Meza, José Ramón Cossío Díaz, César Esquinca Muñoa, Javier Quijano Baz, Manuel Ernesto Saloma Vera y Arturo Zaldívar Lelo de Larrea.

5 "Presentación", en Zaldívar Lelo de LaRrea, Arturo, Hacia una nueva Ley de Amparo, México, UNAM, 2002, p. xii. 
como los entes, organismos y funcionarios públicos que de manera directa disponen de los medios coercitivos para imponer sus determinaciones a los gobernados y, en forma más simple, a los órganos directos del Estado, especialmente de la administración"6.

Este punto de vista también es sostenido en la exposición de motivos del proyecto, donde expresamente se señala: "El derecho administrativo moderno presenta múltiples casos en los que organismos descentralizados e inclusive personas particulares, realizan funciones que originariamente prestaba el Estado y que en su actividad pueden afectar la esfera jurídica de los particulares". Con ese motivo, se explica que el proyecto "propone un concepto abierto que permita su actualización a través de la interpretación jurisdiccional"7.

\section{AnteCEDENTES EUROPEOS}

\section{A) Alemania}

En 1958 el Tribunal Constitucional resolvió el caso Lüth-Urteil. El presidente del Club de Prensa de Hamburgo, Eric Lüth, exhortó al público alemán a "boicotear" una película del cineasta Veit Harlan, a quien acusaba por su pasado nazi ${ }^{8}$. Demandado civilmente, Lüth fue encontrado

6 "La defensa jurídica de los particulares frente a los organismos paraestatales", en Revista de la Facultad de Derecho, México, UNAM, enero-junio de 1984, Nos. 133-135, p. 136. Por lo demás, el maestro Fix-ZAmudio ha abundado sobre este tema. Véase, por ejemplo, "Hacia una nueva ley de amparo", en Estudios en homenaje a don Manuel Gutiérrez de Velasco, México, UNAM, 2000, esp. pp. 327, donde alude al anticuado concepto de autoridad que recoge la ley vigente, y 332 , con relación a la protección de los derechos humanos respecto de grupos sociales en situación de dominio.

7 Proyecto de la Suprema Corte de Justicia de la Nación de la Ley de Amparo reglamentaria de los artículos 103 y 107 de la Constitución Política de los Estados Unidos Mexicanos, SCJN, México, 2001, p. 35. Sobre este tema puede verse Zaldívar Lelo de Larrea, Arturo, Hacia una nueva ley de Amaparo, México, UNAM, 2002 , pp. 65 y ss.

8 HARLAN dirigió numerosas películas de propaganda nazi, entre ellas la muy criticada Jud Suss, filmada en 1940, de fuerte contenido antisemita. 
culpable de daño en perjuicio de Harlan. Al conocer el asunto, mediante un recurso constitucional (Verfassungsbeschwerde), el Tribunal examinó las tesis contrapuestas de que los derechos fundamentales se ejercen ante el Estado, y de que, por el contrario, están presentes también en las relaciones de derecho privado ${ }^{9}$. Las consideraciones formuladas por el Tribunal son de gran importancia, y se transcriben parcialmente ${ }^{10}$ :

La cuestión fundamental de si las normas de derechos fundamentales tienen efectos sobre el derecho civil y cómo se debe entender ese efecto en particular, es discutible... Las posiciones más extremas en esta discusión se basan de una parte en la tesis de que los derechos fundamentales se dirigen exclusivamente en contra del Estado, y de la otra, en la idea de que los derechos fundamentales, o algunos, y en todo caso los más importantes, son válidos en las relaciones privadas frente a cualquier persona...

Sin duda los derechos fundamentales se encuentran destinados a asegurar ante todo la esfera de libertad de los individuos frente a las intervenciones de los poderes públicos; son derechos de defensa de los ciudadanos en contra del Estado...

Igualmente es cierto que la Ley Fundamental, que no tiene el carácter de un ordenamiento de valores neutral, en su capítulo sobre derechos fundamentales, ha incluido también un orden de valores objetivo que implica, en principio, un fortalecimiento de los derechos fundamentales. Este sistema de valores, que encuentra su punto medio al interior de la comunidad social, en el libre desarrollo de la personalidad y la dignidad del ser humano, como decisión constitucional fundamental, debe ser válido para todas las esferas del derecho...

${ }^{9}$ El Tribunal del Trabajo venía sosteniendo, desde algunos años antes, que los derechos fundamentales también son exigibles en la relación entre particulares. Véase García Torres, Jesús, y Jiménez-Blanco, Antonio, Derechos fundamentales y relaciones entre particulares, Madrid, Civitas, 1986, pp. 26 y ss.

10 Textos tomados de Schwabe, Jürgen, Cincuenta años de jurisprudencia del Tribunal Constitucional federal alemán, Bogotá, Ediciones Jurídicas Gustavo Ibáñez - Fundación Konrad Adenauer, 2003, pp. 133 y ss. 
La expresión de una opinión, entendida así, en su puro efecto espiritual, es como tal, libre; pero cuando a través de ella se perjudica un bien jurídico, protegido legalmente, de un tercero, cuya protección prevalece sobre la libertad de opinión, entonces no se podrá permitir esa intervención por el hecho de que se dé a través de la expresión de una opinión. Se requiere, por consiguiente, una "ponderación de los bienes jurídicos". El derecho a expresar opiniones debe ceder frente a los intereses de superior rango de un tercero, y que pueden resultar violados con el ejercicio de la libertad de opinión.

A raíz de esa sentencia, que se mantuvo en los límites de la prudencia, se discutió hasta qué punto los particulares pueden afectar los derechos fundamentales de otras personas, y cómo remediar esa situación en el caso de corroborarla. Una tendencia se inclinó en sentido adverso a la Drittwirkung (efecto frente a terceros de los derechos fundamentales), aduciendo que con ella se produce la "disolución" de la Constitución ${ }^{11}$, mientras que otro sector de la doctrina alemana sustenta que la afectación de derechos fundamentales por parte de particulares es atribuible, en última instancia, al Estado, por no haber prevenido adecuadamente esa posibilidad; por ende la defensa de los derechos ante otros particulares es también una forma de defensa ante el Estado por su imprevisión o su incapacidad para evitar el daño ${ }^{12}$.

\section{B) España}

En 1981, con motivo de un amparo ${ }^{13}$ relacionado con la libertad de cátedra, Francisco Tomás y Valiente formuló

11 García Torres, op. cit., p. 33. Por su parte KonRad Hesse, magistrado del Tribunal Constitucional entre 1975 y 1987, manifiesta que la jurisprudencia de ese Tribunal ha abierto ampliamente el derecho privado a la influencia del constitucional, pero con costes importantes. Derecho constitucional y derecho privado, Madrid, Civitas, 1995, p. 59.

12 Cfr. Kommers, Donald P., The constitutional jurisprudence of the Federal Republic of Germany, Durham, Duke University, 1997, p. 368.

${ }_{13}$ Sentencia 5/1981, publicada el 24/02/1981, BOE 47. 
un voto particular, al que se adhirieron los magistrados Ángel Latorre Segura, Manuel Díez de Velasco y Plácido Fernández Viagas, en que dejaba ver una clara semejanza con la tesis alemana de la Drittwirkung:

En ocasiones, el miembro de la comunidad escolar que considere violado alguno de sus derechos fundamentales o libertades públicas en materia educativa cuando se trate de centros privados, podrá encontrar notables dificultades para que aquella presunta violación originada, por ejemplo, en un acto del titular o director del centro que obviamente no son poderes públicos, se plasme en un acto de los poderes públicos, contra el cual tendría ya abierto, previo agotamiento de la vía judicial procedente, el cauce de los recursos de amparo...

En 1982 se produjo un giro relevante. La sentencia del caso $2 / 1982^{14}$ estableció:

Ni la libertad de pensamiento ni el derecho de reunión y manifestación comprenden la posibilidad de ejercer sobre terceros una violencia moral de alcance intimidatorio, porque ello es contrario a bienes constitucionalmente protegidos como la dignidad de la persona y su derecho a la integridad moral (arts. $10 \mathrm{y}$ 15 de la C. E.) que han de respetar no sólo los poderes públicos, sino también los ciudadanos, de acuerdo con los artículos 9 y 10 de la norma fundamental. Un límite de cada derecho es respetar el derecho de los demás, y aunque esta delimitación de esferas pueda ser de difícil concreción en cada caso, tal dificultad no se presenta en el que es objeto de consideración.

En el caso 78/1982 ${ }^{15}$, relacionado con el ejercicio de la libertad de sindicación, el Tribunal inició el fundamento de su sentencia diciendo:

Fundamentos jurídicos: 1 . El primer punto que debemos abordar es el planteado por la empresa "Ford España, S.A.”, en orden a determinar si la cuestión suscitada excede o no del ámbito del recurso, por entender que

14 Publicada el 26/02/1982, BOE 49.

${ }_{15}$ Publicada el 15/01/1983, BOE 13. 
el amparo no se solicita respecto de una resolución judicial sino frente a actos de un particular (antecedente séptimo); actos que - como tales - no son susceptibles de amparo, dado que este recurso limita su ámbito a la protección de los ciudadanos frente a las violaciones de los derechos o libertades originados por disposiciones, actos jurídicos o simple vía de hecho de los poderes públicos, y no por actuaciones de los particulares. La Sala no puede compartir la afirmación de que el recurso no se dirige contra una resolución de un poder público. Basta leer la demanda, y su suplico, para poder afirmar que el objeto del recurso es la Sentencia del Tribunal Central de Trabajo de 30 de enero de 1982, en cuanto revoca la de Magistratura y con ello infringe, a juicio del actor, el derecho de representación sindical. Problema distinto, del que trataremos más adelante, es que al concretar su pretensión el actor solicite en alguna de sus peticiones (Antecedente 1) que el Tribunal haga declaraciones relativas a la nulidad de la actuación de la empresa, lo que como veremos sí puede exceder del ámbito del recurso de amparo, tal y como aparece delimitado por el art. 41 de la Ley Orgánica del Tribunal Constitucional.

... para decidir el contenido del fallo hemos de tener en cuenta diversos extremos, como son los siguientes: En primer lugar, que el objeto del recurso es la Sentencia impugnada por lo que hemos de decidir sobre su constitucionalidad, y no sobre la validez o nulidad de la actuación de la empresa como pretende el recurrente (antecedente $1, \mathrm{~A})$...

En diferentes fallos se ha aludido ya expresamente a la Drittwirkung. Así ocurrió en el caso 56/1995 ${ }^{16}$, en el que se demandaba la vulneración de derechos fundamentales por parte de organizaciones políticas. Entre los antecedentes del fallo se dijo:

... alega el Ministerio Fiscal que, aunque las vulneraciones constitucionales alegadas fueron -en su caso- motivadas directamente por la Asamblea nacional del

16 Publicada el 31/03/1995, BOE 77. 
EAJ/PNV, su acceso al recurso de amparo se basa en la lesión indirecta de los derechos fundamentales causada por las resoluciones judiciales que no otorgaron la tutela debida a tales derechos. Este Tribunal — se recuerdaha reconocido tal posibilidad en numerosas ocasiones, recogiendo lo que en la doctrina alemana se conoce con el nombre de Drittwirkung (por todas, SSTC 2/1982 y 18/1984).

\section{C) Portugal}

En Portugal el Tribunal Constitucional fue creado por la Constitución de 1976; en esa misma norma suprema, desde su origen, se estableció (artículo 18-1) que "Los preceptos constitucionales concernientes a los derechos, libertades y garantías son directamente aplicables y vinculan a las entidades públicas y privadas".

Según J. J. Gomes Canotilho ${ }^{17}$, los criterios jurisprudenciales para la aplicación de esa norma, todavía no se han perfilado con nitidez. Esta es una llamativa paradoja, en tanto que el Tribunal Constitucional ha estado más retraído que en los casos en que no existe disposición constitucional expresa sobre la materia. En todo caso hay algunas sentencias aisladas (198/85; 569/98) donde se han resuelto casos concretos relacionados con la aplicación de ese precepto.

\section{D) Unión Europea}

En la Unión Europea también se observa una clara tendencia en el sentido de extender los efectos de la protección de los derechos humanos ante particulares. La doctrina de la acción positiva del Estado, en el sentido de que el Estado no sólo está obligado a abstenerse de violar los derechos fundamentales, sino que también debe ac-

${ }_{17}$ Direito Constitucional e teoría da Constituicao, Coimbra, Almedina, 2003, p. 1292 . 
tuar para evitar que otros lo hagan, se ha venido abriendo paso en la jurisprudencia de la Corte Europea de Derechos Humanos.

En el caso Young, James y Webster v. U. K., $(1981)^{18}$, la Corte Europea resolvió:

De acuerdo con el artículo 1 de la Convención Europea de Derechos Humanos, cada Estado contratante "debe asegurar a cada persona, dentro de su jurisdicción, los derechos y las libertades definidas en (...) la Convención"; por tanto, si la violación de uno de esos derechos y libertades es el resultado de la inobservancia de esa obligación en cuanto a la legislación doméstica, existe responsabilidad para el Estado que consiente la violación. A pesar de que la causa inmediata de los hechos que dan lugar a esta causa fueron los acuerdos entre la empresa British Rail y los sindicatos ferrocarrileros, fue la ley doméstica aplicable en el momento la que hizo legal el perjuicio que los demandantes sufrieron. La responsabilidad del Estado acusado por cualquier violación de lo dispuesto por la Convención se deriva de esa circunstancia.

Años después, en el caso $X y Y v$. Netherlands ${ }^{19}$, resuelto en 1985, la Corte resolvió en estos términos:

La Corte ratifica que, no obstante que el propósito del artículo 8 (de la Convención Europea de Derechos Humanos) es esencialmente la protección de los individuos contra la acción arbitraria de las autoridades públicas, eso no significa que el Estado sólo se abstenga de actuar en esa forma; además de su obligación negativa, también hay obligaciones positivas inherentes al respeto efectivo de las personas y de las familias. Esa obligación incluye

18 El asunto planteado consistía en que un grupo de trabajadores denunció, como violatoria de sus derechos, la cláusula de exclusión (closed shop) pactada entre el sindicato y la empresa; conforme a esa cláusula todos los trabajadores deberían afiliarse al sindicato contratante.

${ }_{19}$ Número 16/1983/72/110. El señor X denunció que su hija, Y, menor de edad internada en una clínica particular para personas con retraso mental, había sido violada por el hijo, mayor de edad, de la responsable de la institución. Las autoridades se negaron a iniciar el procedimiento penal alegando que $\mathrm{Y}$ carecía de facultades mentales para formular una acusación. 
la adopción de medidas destinadas a asegurar el respeto de la vida privada incluso en la esfera de relaciones entre particulares.

En 1988 se resolvió el caso Plattform "Ärzte für das Leben" v Austria ${ }^{20}$, y se tomó una posición más avanzada todavía, pues se sostuvo que el Estado no debía adoptar una actitud pasiva ante hechos violatorios de los derechos fundamentales:

Una manifestación puede afectar $\mathrm{u}$ ofender a personas con ideas opuestas a las sustentadas por los manifestantes. Los participantes, sin embargo, deben contar con la seguridad de poderse manifestar sin el temor de ser objeto de violencia física por parte de sus oponentes, porque ese temor inhibiría a las organizaciones de expresar libremente sus opiniones sobre cuestiones altamente controvertidas que afecten a la comunidad. En una democracia el derecho a las contra-manifestaciones no puede permitirse hasta el extremo de inhibir el derecho de los manifestantes originales. La genuina y efectiva libertad de manifestación no se reduce al deber del Estado de no interferir; una concepción estrictamente negativa no es compatible con los propósitos del artículo 11 (de la Convención Europea de Derechos Humanos). Igual que el artículo 8 , el 11 requiere en ocasiones de medidas positivas, incluso en la esfera de las relaciones entre particulares.

La Corte se apartó del criterio relativo a la responsabilidad de los particulares, en el caso Gustafsson v. Swe$d e n^{21}$. El juez P. Jambrek, sin embargo, formuló un voto disidente en estos términos:

Mi posición difiere en cuanto a la interpretación y a la aplicación del artículo 11 (de la Convención Europea de

${ }^{20}$ Número de causa 5/1987/128/179. La organización Plattform "Ärzte für das Leben" era una asociación de médicos antiabortistas, que organizó manifestaciones en 1980 y 1982; en ambos casos sufrieron ataques por parte de otros grupos, partidarios del aborto, ante la presencia pasiva de grandes contingentes policiales

${ }^{21}$ Número 18/1995/524/610. Se trató de un conflicto entre el propietario de un restaurante y una organización de restauranteros que, por no estar afiliado, pretendió boicotearlo para obligarlo a incorporarse al grupo. 
Derechos Humanos), a la luz de la doctrina de la Drittwirkung. Desde mi punto de vista, la acción de los industriales que dio lugar a la queja del demandante debe estar sujeta a las mismas restricciones que se aplican al Estado. El Estado responsable (Holanda) estaba en la obligación positiva de tomar medidas que aseguraran el disfrute de la libertad de asociación.

\section{ANTECEDENTES ASIÁTICOS}

En Japón ha habido una importante tendencia en el sentido de adoptar los principios de la Drittwirkung. La influencia francesa y alemana en la legislación civil ha sido una constante en ese país desde finales del siglo XIX. El Código Civil se abre con una categórica declaración (artículo $1^{-}$-I) en el sentido de que los derechos privados están sujetos al principio del bienestar público, y el artículo 90 dispone la nulidad de los contrato contrarios al interés público.

Esos preceptos han sido invocados ante los tribunales para defender los derechos fundamentales frente a particulares, y se ha encontrado una gran receptividad. A partir de 1993 se registran casos en los que diversos tratados internacionales en materia de derechos humanos han dado lugar a demandas en contra de particulares a quienes se han atribuido actos contrarios a esos derechos ${ }^{22}$.

En el primer caso, en 1993, la Corte de Distrito de Osaka resolvió a favor de un coreano a quien se negó el arrendamiento de un departamento a causa de su nacionalidad. En otro asunto una trabajadora invocó las recomendaciones de la Organización Internacional del Trabajo para evitar que la empresa donde trabajaba le aplicara unilateralmente una decisión de jubilarla; en esta ocasión el tribunal falló en contra de la actora, pero sobre la base de que las "recomendaciones" no son una norma internacional. Un tercer caso se presentó en contra de la empresa Nissan, a

22 IwaSAWA, Yuj, International law, human rights and Japanese law, Oxford, Clarendon Press, 1998, pp. 89 y ss. 
la que se acusó, con éxito, por practicar una política discriminatoria en perjuicio de las mujeres, a las que obligaba a retirarse a los cincuenta y cinco años de edad, mientras que para los hombres fijó en sesenta la edad de retiro.

\section{ANTECEDENTES AMERICANOS}

El maestro Fix-Zamudio ha identificado que la protección de los derechos fundamentales frente a particulares se ha expandido considerablemente, a través de la norma constitucional o de la ley ordinaria, en numerosos países latinoamericanos ${ }^{23}$. Se trata, por ende, de una tendencia muy consistente que apunta en el sentido de seguirse desarrollando.

\section{A) Argentina}

En 1958 la Corte Suprema de la Nación resolvió el caso Kot. Este caso tenía como origen un conflicto laboral entre la empresa Samuel Kot S. R. L. y su sindicato. Los trabajadores tomaron las instalaciones de la empresa, pero permitían el acceso a los patrones. Cuando el asunto fue sometido al conocimiento de la Corte, la mayoría de sus integrantes razonó asíi ${ }^{24}$ :

Es verosímil presumir que en el ánimo de los constituyentes de 1853 , las garantías constitucionales tuvieran como inmediata finalidad la protección de los derechos esenciales del individuo contra los excesos de la autoridad pública ${ }^{25}$. En el tiempo en que la Constitución fue dictada, frente al individuo solo e iner-

${ }^{23}$ Fix-Zamudio, Héctor, Ensayos sobre el derecho de amparo, México, UNAM - Porrúa, 2003, pp. 786 y ss.

24 Textos tomados de LaZZARInI, José Luis, El juicio de amparo, Buenos Aires, La Ley, 1987, pp. 26 y ss.

${ }^{25} \mathrm{El}$ artículo 33 de aquella Constitución decía: "Las declaraciones, derechos y garantías que enumera esta Constitución no serán entendidos como negación de otros derechos y garantías no enumerados, pero que nacen del principio de la soberanía y de la forma republicana de gobierno". 
me no había otra amenaza verosímil e inminente que la del Estado.

Nada hay, ni en la letra ni en el espíritu de la Constitución, que permita afirmar que la protección de los llamados "derechos humanos" esté circunscrita a los ataques que provengan sólo de la autoridad. Nada hay, tampoco, que autorice la afirmación de que el ataque ilegítimo, grave y manifiesto contra cualquiera de los derechos que integran la libertad, lato sensu, carezca de la protección constitucional adecuada... por la sola circunstancia de que ese ataque emane de otros particulares o de grupos organizados de individuos.

Además de los individuos humanos y del Estado, hay ahora una tercera categoría de sujetos, con o sin personalidad jurídica, que sólo raramente conocieron los siglos anteriores: los consorcios, los sindicatos, las asociaciones profesionales, las grandes empresas, que acumulan casi siempre un enorme poderío material o económico... Estos entes colectivos representan una fuente de amenazas para el individuo y sus derechos esenciales...

Poco antes del caso Kot, la Convención Constituyente Nacional, reunida en Santa Fé (1957), propuso adicionar el artículo 18 de la Constitución, en los siguientes términos: "Toda persona podrá obtener el amparo de sus derechos individuales consagrados en esta Constitución promoviendo por sí o por conducto de un tercero, ... acción de amparo. Los jueces tienen obligación ineludible de prestar inmediatamente ese amparo en sus respectivas jurisdicciones contra toda privación o amenaza de la libertad contraria a esta Constitución, ya provenga de actos o de omisión de autoridad o de particulares".

Aun cuando esa reforma no fue adoptada, tuvo un claro impacto en la legislación ordinaria y en los textos constitucionales federal y provinciales posteriores ${ }^{26}$. El Código Procesal Civil y Comercial de 1967, por ejemplo, introdujo

${ }^{26}$ Entre las constituciones provinciales, previas a la nacional, que incorporaron el amparo contra particulares, figuran la de Salta (1986), en cuyo artículo 87 se dispone: "La acción de amparo procede frente a cualquier decisión, acto u 


\section{el amparo contra actos de particulares. Por la naturaleza federal de esta norma, se produjeron numeroso problemas}

omisión arbitrarios o ilegales de la autoridad, excepto la judicial, o de particulares, restrictivos o negatorios de las garantías y derechos subjetivos explícitos o implícitos de esta Constitución, tanto en el caso de una amenaza inminente cuanto en el de una lesión consumada, a los fines del cese de la amenaza o del efecto consumado. (...) El Juez de amparo escucha a la autoridad o particular de quien provenga la amenaza o la restricción en un plazo breve y perentorio, pudiendo habilitar al efecto horas y días inhábiles."

La Constitución de San Juan (1986) establece en su artículo 40: "Procede la acción de amparo contra todo acto u omisión de autoridad, órganos o agentes públicos, de grupo organizado de personas y de particulares que, en forma actual o inminente, lesione o restrinja, altere o amenace con arbitrariedad o ilegalidad manifiesta algún derecho individual o colectivo o garantía explícita o implícitamente reconocidos por la Constitución Nacional o Provincial, siempre que fuera necesaria la reparación urgente del perjuicio, la cesación inmediata de los efectos del acto o la prohibición de realizar un acto ilegal y la cuestión por su naturaleza, no deba sustanciarse por alguno de los procesos establecidos por la ley o no resultare eficaz hacerlo."

La de La Rioja (1986), señala en su artículo 28 que el amparo: "Procederá la acción de amparo contra cualquier decisión, acto u omisión de autoridad o de particulares que, con manifiesta ilegalidad o arbitrariedad, pusiere en peligro actual o inminente, restringiere, limitare o amenazare el ejercicio de los derechos reconocidos en esta Constitución o en la Constitución Nacional, a fin de que el Juez arbitre los medios para el inmediato restablecimiento del ejercicio del derecho afectado. Esta acción procederá siempre que no pudieren utilizarse por razones de urgencia los medios ordinarios sin daño grave e irreparable y no procediese el recurso de Hábeas Corpus."

A su vez la de Tierra de Fuego (1991), dispone en el artículo 43 que: "Siempre que en forma actual o inminente se restrinjan, alteren, amenacen o lesionen, con arbitrariedad o ilegalidad manifiestas, derechos o garantías reconocidos en la Constitución Nacional y en esta Constitución, y no exista otra vía pronta y eficaz para evitar un grave daño, la persona afectada podrá pedir el amparo a los jueces en la forma sumarísima que determine la ley." En este caso no se hace referencia expresa a los particulares, pero el contenido del precepto es lo suficientemente amplio para incluir a los particulares.

En cuanto a las constituciones posteriores a la nacional, la de Córdoba (2001), siguió la pauta de Tierra de Fuego al disponer, en el artículo 48: "Siempre que en forma actual o inminente se restrinjan, alteren, amenacen o lesionen, con arbitrariedad o ilegalidad manifiesta, derechos o garantías reconocidos por esta Constitución o por la Constitución Nacional, y no exista por otra vía pronta y eficaz para evitar un grave daño, la persona afectada puede pedir el amparo a los jueces en la forma que determine la ley." Otro tanto hizo la de Santa Cruz (1998), cuyo artículo 15 señala: "Los Jueces prestarán amparo a todo derecho reconocido por la Constitución Nacional y ésta, y si no hubiera reglamentación o procedimiento legal, arbitrará a ese efecto trámites breves.”

Otras constituciones siguen el ejemplo de la nacional. La Constitución de la Provincia de Buenos Aires, en su artículo 20.2 establece: "La garantía de Ampa- 
en cuanto a su aplicación ${ }^{27}$; la referencia en este caso es sólo para ilustrar el efecto expansivo que tuvo la jurisprudencia con relación a la ley.

\section{B) Colombia}

El artículo 86 de la Constitución colombiana determinó: "La ley establecerá los casos en que la acción de tutela procede contra particulares encargados de la prestación de un servicio público o cuya conducta afecte grave y directamente el interés colectivo, o respecto de quienes el solicitante se halle en estado de subordinación o de indefensión". Al efecto, la ley reglamentaria desarrolló el precepto y, al comenzar su aplicación, la Corte Constitucional entendió que la enunciación era taxativa y circunscribía la acción de tutela ante particulares sólo a los casos legalmente admitidos. El criterio jurisprudencial cambió poco después ${ }^{28}$, cuando la Corte resolvió:

Resulta un contrasentido que el legislador, desconociendo el espíritu del Constituyente y uno de los propósi-

ro podrá ser ejercida por el Estado en sentido lato o por particulares, cuando por cualquier acto, hecho, decisión u omisión, proveniente de autoridad pública o de persona privada, se lesione o amenace, en forma actual o inminente con arbitrariedad o ilegalidad manifiesta, el ejercicio de los derechos constitucionales individuales y colectivos."

Y, dentro de estos ejemplos, la Constitución de la Ciudad de Buenos Aires (1996), indica en su artículo 14: "Toda persona puede ejercer acción expedita, rápida y gratuita de amparo, siempre que no exista otro medio judicial más idóneo, contra todo acto u omisión de autoridades públicas o de particulares que en forma actual o inminente, lesione, restrinja, altere o amenace con arbitrariedad o ilegalidad manifiesta, derechos y garantías reconocidos por la Constitución Nacional, los tratados internacionales, las leyes de la Nación, la presente Constitución, las leyes dictadas en su consecuencia y los tratados interjurisdiccionales en los que la Ciudad sea parte."

${ }^{27}$ Cfr. Bidart CAmpos, GeRmán J., Régimen legal y jurisprudencial del amparo, Buenos Aires, Ediar, 1968, p. 109 y ss.

${ }^{28}$ Caso SC-134/94, citado por Estrada, AleXei Julio, La eficacia de los derechos fundamentales entre particulares, Bogotá, Universidad Externado de Colombia, 2000, p. 232. Numerosos ejemplos, en la misma dirección, son ofrecidos por Cifuentes Muñoz, EduARDo, La eficacia de los derechos fundamentales ante particulares, México, UNAM, 1998, esp. pp. 23 y ss. 
tos fundamentales del nuevo ordenamiento constitucional colombiano, pretenda limitar el radio de la acción de tutela, al señalar en forma taxativa aquellos derechos fundamentales que, a su juicio, puedan ser amparados cuando la conducta nociva provenga de un particular (...) No era atribución de la ley, so pretexto de dar protección a un mandato constitucional, determinar los derechos fundamentales que pueden ser invocados por el solicitante cuando el sujeto pasivo de la tutela es un particular, pues conviene señalarlo, los derechos fundamentales son la base, el sustento de toda legislación, y no su efecto. Si la acción de tutela procede para proteger los derechos fundamentales de las personas, entonces no resulta lógico realizar una diferenciación respecto de cuáles derechos pueden ser amparados y cuáles no (...) La acción de tutela contra particulares es viable cuando se intente proteger, dentro de las tres situaciones fácticas que contempla la norma constitucional, cualquier derecho constitucional fundamental, sin discriminación alguna.

Puede advertirse que, en el caso colombiano, la norma precedió a la jurisprudencia, pero fue ésta la que amplió el alcance de la disposición constitucional.

\section{C) El Salvador}

En El Salvador la Constitución dispone, en su artículo 247, que "toda persona puede pedir amparo ante la Sala de los Constitucional de la Corte Suprema de Justicia, por violación de los derechos que otorga la presente Constitución". Con fundamento en este precepto fueron promovidos diversos juicios de amparo. Uno, en particular, resulta especialmente interesante por cuanto a la resolución de la Sala ${ }^{29}$.

Para el caso de este Tribunal, el objeto de la pretensión constitucional de amparo, en primer lugar, debe te-

${ }^{29}$ Caso 213-98/216-98 M, promovido en contra de la Asociación Cafetalera del El Salvador, por dos de sus miembros, que fueron expulsados sin respetarles su derecho de audiencia y en perjuicio de su libertad de asociación. Fue resuelto en junio de 2000. Los textos en cursiva y los subrayados aparecen así en la sentencia; las negritas son del autor. 
ner trascendencia constitucional; en segundo lugar, la reclamación con este tipo de trascendencia debe haberse intentado atacar por las vías existentes en el ordenamiento jurídico; $y$, por último, que el objeto sea la revisión de un acto que reúna las características de una "acto de autoridad".

Especial mención merece este último requisito del objeto de la pretensión de amparo. A saber: en jurisprudencia constitucional anterior se consideraba que "acto de autoridad" era aquél emitido por personas o instituciones (órgano institución $u$ órgano persona) que formen parte de alguno de los Órganos del Estado o que realicen actos por delegación de los mismos, mediando con el gobernado una relación de supra a subordinación, con lo cual se desechaba cualquier posibilidad de promover amparo contra un acto emitido por un particular.

$\mathrm{Al}$ respecto, en la jurisprudencia dictada a las catorce horas y cinco minutos del día veintidós de mayo de mil novecientos noventa y seis, en el proceso calificado bajo el número de referencia 10-L-96, se señala que para los efectos del proceso de amparo "... el concepto de autoridad comprende aquellas personas o instituciones que forman parte de alguno de los Órganos del Estado, o que realicen actos de autoridad por delegación de los mismos; es decir, que hagan uso de la facultad de imperio del Estado, y que realicen actos unilaterales y coercitivos que se impongan a los gobernados...”.

Sin embargo, la jurisprudencia de este Tribunal evolucionó. Así, frente al planteamiento de amparos en los cuales se advertían posibles violaciones a derechos constitucionales de los gobernados, por actos emitidos por particulares, comenzaron a producirse resoluciones de avanzada que van más allá del contenido literal del artículo 12 de la Ley de Procedimientos Constitucionales y del mismo artículo 247 de la Constitución, con la finalidad esencial de ampliar el espectro de procedencia del objeto de la pretensión de amparo, interpretando que la disposición constitucional no hace alusión a la fuente de la violación, mucho menos establece alguna cláusula de cierre para entender que sólo procede el amparo contra actos emitidos por autoridades 
propiamente dichas (autoridades públicas legalmente constituidas).

$\mathrm{Y}$ es que, del estudio exhaustivo de las pretensiones incoadas, se advirtieron casos en los cuales algunos particulares producían actos limitativos de derechos constitucionales de los gobernados, como si se tratase de verdaderos actos de autoridad desde un punto de vista material, es decir, se advirtieron casos en los cuales el objeto de la pretensión era la revisión de actos que salían fuera del concepto tradicional de "actos de autoridad", pero que sin embargo limitaban definitiva y unilateralmente derechos constitucionales.

En efecto, en el proceso de amparo 143-98 se admitió la demanda contra un acto emitido por un particular en resolución de las ocho horas treinta minutos del día uno de junio de mil novecientos noventa y ocho. El motivo central para admitir la demanda, esencial y textualmente, fue: “... el concepto de autoridad y por consiguiente los actos de la misma, no pueden ser exclusivamente formales; esto es, atender a que efectivamente forme parte de alguno de los órganos del Estado, sino además, debe ser un concepto material, de tal manera que comprenda aquellas situaciones en las que personas o instituciones que formalmente no sean autoridad, sean materialmente consideradas como tales".

En virtud de lo anterior, es menester ahora consolidar la jurisprudencia en relación a los casos en que, no obstante ser el objeto de la pretensión la reclamación de un acto emitido por un particular, puede entrarse a conocer el asunto por existencia de competencia material, esbozando algunas ideas más alrededor de las características propias del acto del particular para que sea considerado como "acto de autoridad" (acto revisable en amparo constitucional). $\mathrm{Y}$ es que, es menester que esta Sala deje establecido, aunque de manera abstracta y en forma de numerus apertus, los supuestos en lo cuales puede solicitarse amparo no obstante ser el objeto de la pretensión el control constitucional de una acto emitido por un particular.

En efecto, así como el "acto de autoridad" debe de reunir ciertos requisitos, como que sea emitido con supuestas vulneraciones a derechos constitucionales, que se 
haya hecho uso de todos los recursos o remedios para atacarlo y que estando dentro de una de estas vías, éste se haya agotado plenamente; también el "acto de autoridad" emitido por un particular debe reunir ciertos requisitos para poder encajar dentro de la competencia material de esta Sala, aunque algunos de aquéllos tengan su coincidencia con los relacionados inicialmente para el acto de autoridad tradicional. Y es que no puede dejarse por completo abierta la puerta en estos casos, puesto que el amparo constitucional se constituiría en mecanismo absoluto de satisfacción de pretensiones sin trascendencia constitucional. Ahora bien, hay que dejar claro desde ya que si un acto de particular es rechazado en un proceso de amparo, será porque no reúne el objeto de la pretensión las condiciones necesarias para su revisión desde un punto de vista constitucional, y no por falta de legitimación pasiva, pues esta se adquiere con sólo el hecho de ser la fuente de emisión del acto.

Así, en términos generales, puede afirmarse que el objeto de la pretensión de amparo procede contra actos de particulares cuyas exteriorizaciones, por lógica, no responderán a las manifestaciones y dimensiones propias de los actos de autoridad; mas, tendrán similares repercusiones en la esfera jurídica del pretensor. Entonces, abstracción hecha de los formalismos que debe reunir toda demanda de amparo, contemplados en el artículo 14 de la Ley de Procedimientos Constitucionales, si ésta contiene como objeto de la pretensión la reclamación frente a un acto emitido por un particular, puede rechazarse por los siguientes motivos: (a) si no se han hecho uso de los remedios o recursos que el ordenamiento jurídico establece para atacarlo y si, estando una de esas vías en trámite, no se ha agotado plenamente; (b) si se trata de una simple inconformidad con el contenido del acto; $y$ (c) siempre y cuando el particular que emitió el acto no se encuentre en "situación" de supra a subordinación material respecto del gobernado.

(a) El objeto de la pretensión de amparo dirigido contra un acto emitido por un particular, se rechazará si hay otros remedios o recursos administrativos, procesales o procedimentales para reparar 
el supuesto perjuicio constitucional ocasionado, y éstos no han sido utilizados o están en trámite. En efecto, no puede pretenderse que se revisen actuaciones si existen mecanismos de jurisdicción ordinaria o administrativos establecidos precisamente para tal fin, pues en estos supuestos con la improcedencia de la demanda de amparo no se estarían creando zonas exentas de control. Además, es bien sabido el carácter subsidiario del proceso de amparo, el cual implica que sólo abre su competencia material cuando ha sido imposible la reparación del daño constitucional en las sedes ordinarias.

(b) El amparo contra acto de un particular es improcedente cuando el mismo no es manifiestamente arbitrario o ilegítimo, sino que ha sido dictado dentro del marco de sus atribuciones. Esto nos lleva, en consecuencia, a determinar también que el objeto de una pretensión de amparo dirigido frente a un acto de particular puede ser rechazado si se reduce en una simple inconformidad con el contenido del mismo o se pretende utilizar el amparo constitucional como un grado de conocimiento material y superior del particular emisor del acto, situación análoga a la mera legalidad en los amparos contra autoridades legalmente establecidas. Y es que no se puede invadir, aunque se trate de particulares, esferas propias de su competencia.

(c) Para explicar adecuadamente este punto, hay que decir que en la relación entre particulares muchas veces una de las partes no tiene, de hecho, más alternativa que aceptar un acto dictado unilateralmente, pues la fuente de emisión posee el poder de imponer a otros sus propias decisiones; es decir, que ostenta una posición de predominio tal que puede comprometer e, incluso, anular el ejercicio efectivo de muchos derechos materiales constitucionales, cuando de ese poder dependen exclusivamente el ejercicio efectivo de aquéllos.

Por la razón anteriormente expuesta, en estos casos, y en función de los derechos constitucionales oponibles a esta clase de sujetos pasivos, podría decirse que la rela- 
ción entre el particular afectado y la persona o entidad emisora, no es de carácter horizontal, sino más bien vertical, puesto que las situaciones de poder son análogas a las establecidas en la relación Estado-gobernado.

En efecto, el objeto de la pretensión dirigido frente a un acto de particular puede rechazarse si éste está actuando como simple entidad, persona natural o jurídica privada dentro de sus específicas atribuciones, sin que dichas actuaciones conlleven a situaciones de supra-subordinación en relación al ejercicio efectivo de los derechos materiales que otorga nuestra Constitución a los gobernados.

$\mathrm{Al}$ contrario, el objeto de aquella pretensión es procedente si el particular es la única instancia de desarrollo de algún derecho constitucional protegible a través del proceso de amparo. Y es que, de modo inverso, se dejaría fuera del ámbito de competencia material de esta Sala situaciones en las cuales las meras declaraciones subjetivas de voluntad de un particular o sus omisiones voluntarias, determinan el ejercicio efectivo de un derecho constitucional, precisamente por ser el único medio de realización de los mismos. Ello es así, porque aun en estas situaciones, prevalece la eficacia directa de la Constitución, lo cual implica que aun los actos emanados de particulares en estas condiciones de supra a subordinación material, tienen el deber de no perturbar o impedir el ejercicio efectivos de los derechos constitucionales que les son oponibles; negar la eficacia directa a limine y categóricamente, sería desconocer el carácter normativo de aquélla. Por último, cabe aclarar que bastará la concurrencia de algún vicio de esta naturaleza para rechazar en cualquier estado del proceso la demanda de amparo contra actos de particulares.

\section{D) Otros países latinoamericanos}

La protección de los derechos fundamentales ante particulares ha sido considerada en numerosos sistemas constitucionales latinoamericanos. En algunos casos se ha hecho de manera implícita, dejando amplios márgenes de in- 
terpretación a la autoridad judicial, merced a un concepto amplio por cuanto a quienes pueden afectar esos derechos; en otros casos se ha hecho referencia explícita a los particulares como posibles responsables de los hechos violatorios de derechos fundamentales. Entre los primeros figuran, además del caso ya mencionado de El Salvador, las constituciones de Costa Rica (artículo 48), Guatemala (artículo 265), Honduras (artículo 183), Nicaragua (artículo 45), Uruguay (artículo 10) y Venezuela (artículo 27); entre los segundos, además de Argentina y Colombia, figuran las constituciones de Bolivia (artículo 19), Chile (artículo 20), Ecuador (artículo 95), Paraguay (artículo 134) y Perú (artículo 200.2).

\section{D) Estados Unidos}

En Estados Unidos ha prevalecido el criterio, doctrinario y jurisprudencial, de que la Constitución sólo regula las relaciones entre los órganos del poder, y entre éstos y los ciudadanos, mas no de los ciudadanos entre. Esta tesis, conocida como State action ("acción del Estado"), ha prevalecido secularmente. Se han llegado a plantear casos en los que la apariencia del actor que vulnera los derechos de las personas, es de derecho privado. Eso ocurrió, por ejemplo, en el caso Lebron v. National Railroad Passenger Corp ${ }^{30}$. La Suprema Corte razonó en el sentido de que la empresa era, en realidad, un instrumento gubernamental, aunque el gobierno, al constituirla, la hubiese sujetado a un régimen de derecho privado. "No es admisible, se dijo, que el gobierno, estatal o federal, pueda esquivar las más solemnes obligaciones impuestas por la Constitución mediante el simple expediente de adoptar una forma societaria" 31 .

${ }^{30}$ Caso 115 Sct 961, de 1995. Un artista demandó a la empresa ferroviaria por limitar su derecho de creación y expresión.

${ }^{31}$ Cit. por Bilbao Ubillos, Juan María, Los derechos fundamentales en la frontera entre lo público y lo privado, Madrid, McGRaw-Hill, 1997, p. 34. 
La Corte ha resuelto numerosos casos en los que mantenido una especie de equilibrio entre la State action y muy tímidos intentos por abordar el problema de la violación de derechos por parte de particulares. En uno de esos casos, por ejemplo, se detuvo ante un hecho claramente discriminatorio porque la persona afectada (un negro) al no ser admitida en un restaurante, no solicitó el auxilio de un policía antes de ocurrir ante los tribunales; con esto, se decía, ya habría un acto de autoridad estatal $^{32}$.

Las inconsistencias de la jurisprudencia americana han sido analizadas, entre otros, por Laurence Tribe ${ }^{33}$. En su opinión la jurisprudencia americana en este punto es caótica porque no ha podido superar las barreras que le impone un principio tan rígido como el de la State action. Las bases de esta doctrina, apunta, son esencialmente dos: la garantía absoluta de la libertad privada y los principios del federalismo, que no permite interferir en la vida de los estados, y de la separación de poderes, que sólo permite ejercer actos de control entre los poderes y, en el caso de los tribunales, resolver las cuestiones que surjan entre los particulares y el Estado, y entre ellos entre sí por relaciones de naturaleza privada.

En la actualidad se está produciendo un movimiento doctrinario creciente $^{34}$, en el sentido de revisar el alcance de la State action. La dirección hacia la que apunta tiene mucha semejanza con las bases de la Drittwirkung.

${ }_{32}$ Moose Lodge v. Irvis, 407 U.S. 163 (1972). El demandante adujo que el restaurante operaba con una licencia gubernamental, y por ende era aplicable la doctrina de la State action. La Corte resolvió que la licencia no hacía responsable al gobierno de los actos de los particulares que operaban el lugar, porque una interpretación amplia en ese sentido haría que los responsables de cualquier sitio que dispusiera de servicios de energía eléctrica o de agua, que también se surten mediante autorizaciones y permisos gubernamentales, fuesen considerados como agentes gubernamentales para efectos de su responsabilidad. La debilidad del razonamiento es evidente.

${ }_{33}$ American Constitutional Law, N. York, The Foundation Press, 1988, pp. 1687 y ss.

${ }^{34}$ Cfr. RAtNeR, StEven R., "Corporations and human rights: a theory Of. Legal responsibility”, en Yale Law Journal, vol. 111, No. 3, 2001, y BiLbao UBILLOS, op. cit., pp. 182 y ss. 


\section{E) Sistema interamericano}

En 1987 la Corte Interamericana de Derechos Humanos resolvió el caso Velásquez Rodríguez ${ }^{35}$, y razonó en estos términos:

166. La segunda obligación de los Estados parte es la de "garantizar" el libre y pleno ejercicio de los derechos reconocidos en la Convención (Americana sobre Derechos Humanos) a toda persona sujeta a su jurisdicción. Esta obligación implica el deber de los Estados parte de organizar todo el aparato gubernamental y, en general, todas las estructuras a través de las cuales se manifiesta el ejercicio del poder público, de manera tal que sean capaces de asegurar jurídicamente el libre y pleno ejercicio de los derechos humanos. Como consecuencia de esta obligación los Estados deben prevenir, investigar y sancionar toda violación de los derechos reconocidos por la Convención...

167. La obligación de garantizar el libre y pleno ejercicio de los derechos humanos no se agota con la existencia de un orden normativo dirigido a hacer posible el cumplimiento de esta obligación, sino que comporta la necesidad de una conducta gubernamental que asegure la existencia, en la realidad, de una eficaz garantía del libre ejercicio de los derechos humanos.

173. (...) En efecto, un hecho ilícito violatorio de los derechos humanos que inicialmente no resulte imputable directamente a un Estado, por ejemplo, por ser obra de un particular o por no haberse identificado al autor de la trasgresión, puede acarrear responsabilidad internacional del Estado, no por ese hecho en sí mismo, sino por falta de la debida diligencia para prevenir la violación o para tratarla en los términos requeridos por la Convención.

Puede advertirse como el razonamiento en el sentido de la responsabilidad que resulta por el Estado, por no preve-

${ }^{35}$ Los hechos de la demanda consistían en la desaparición forzada de diversas personas, atribuida a la acción de agentes del Estado hondureño. Se suscitó la cuestión de que los agentes hubieran actuado por su cuenta, o incluso de que hubiesen intervenido personas ajenas al Estado. 
nir o evitar actos de particulares lesivos de los derechos fundamentales, ya cuenta también con precedentes en el sistema interamericano.

\section{CONSIDERACIONES FINALES}

Le tendencia apunta en el sentido de ampliar la competencia de los tribunales para conocer de todo tipo de actos $\mathrm{u}$ omisiones que afecten los derechos fundamentales. Esto es una consecuencia del carácter normativo de la Constitución y de su supremacía. También guarda relación directa con el concepto de justicia que se sustente ${ }^{36}$.

Es previsible que también se produzca un movimiento análogo en el ámbito de los derechos humanos. La restricción que actualmente aparece en el artículo 102 de la Constitución $^{37}$ no es compatible con la ampliación que se propone para los tribunales. Las mismas consideraciones que se han tenido presentes para el desarrollo de la protección jurisdiccional de los derechos fundamentales ante particulares, son válidas para el caso de los organismos no jurisdiccionales que tienen ese mismo cometido.

La protección de los derechos fundamentales ante particulares es una creación jurisprudencial y doctrinaria, que sólo de manera posterior ha venido siendo legislada ${ }^{38}$.

${ }^{36}$ En este punto es relevante la idea de integridad que sustenta RONALD DwoRkin. Para este autor los dos principios de integridad política corresponden, en cuanto a la legislación, a la obligación del legislador de elaborar leyes moralmente coherentes, y en cuanto a la adjudicación, en interpretar la ley en el sentido de esa coherencia. Law's Empire, Londres, Fontana, 1991, pp. 176 y ss.

37 Los organismos protectores de los derechos humanos "conocerán de quejas en contra de actos u omisiones de naturaleza administrativa provenientes de cualquier autoridad o servidor público... que violen esos derechos."

38 PEDRo DE VEGA ha dicho de una manera muy enfática: "Ante las escandalosas omisiones de los textos constitucionales, han tenido que ser la doctrina y la jurisprudencia las que, respondiendo a elementales exigencias de la lógica jurídica, y supliendo esos ominosos silencios, abrieron el camino al reconocimiento de la Drittwirkung", "La eficacia frente a particulares de los derechos fundamentales (la problemática de la Drittwirkung der Grundrechte)", en Carbonell, Miguel (coordinador), Derechos fundamentales y Estado. Memoria del VII Congreso Iberoamericano de Derecho Constitucional, México, UNAM, p. 701. 
En este trabajo he omitido las fuentes de doctrina, para centrar la atención en los diferentes antecedentes jurisprudenciales, y así tener una idea de la forma como este concepto ha migrado a través de diferentes sistemas.

Como puede verse, en el caso de Japón los jueces han acogido las normas internacionales y las aplican cuando unos particulares afectan los derechos de otros.

En el caso de Alemania es importante tener en cuenta que la Constitución dispone (artículo 19-4): “Todo el que se vea lesionado en su derechos por obra del poder público, podrá acudir a la vía judicial." Al adoptar el criterio de la Drittwirkung, el Tribunal Constitucional no pudo sujetarse al texto literal, y se vio obligado a fallar sobre la base del "sistema de valores" incluido en la Constitución.

En cuanto a España, puede apreciarse que el Tribunal Constitucional, desde 1981, comenzaba a orientarse hacia una argumentación parecida a la adoptada por su homólogo alemán, en el sentido de que se pronunciaba sobre el acto de una autoridad, en este caso del tribunal a quo. Son ya numerosas las resoluciones en las que este tema ha sido abordado, con una tendencia claramente inclinada a favor de la defensa de los derechos fundamentales, oponibles también a particulares. Así se haya adoptado una línea oblicua, pronunciándose con relación a un acto de la autoridad jurisdiccional, el caso es que se ha construido una forma eficaz de garantizar los derechos fundamentales cuando se ven amenazados por particulares ${ }^{39}$.

La Constitución española dispone, en su artículo 53.1, que los derechos y libertades por ella reconocidos "vinculan a todos los poderes públicos". Esto no excluye, como lo ha venido desarrollando la jurisprudencia del Tribunal Constitucional, a los entes privados. Ese precepto no se ha entendido en un sentido restrictivo, como si los únicos

39 Alexei Julio Estrada ha observado que, a diferencia de la jurisprudencia española, que se mantiene en un nivel limitado de desarrollo, la alemana ha generado un efecto de irradiación conforme al cual "no hay ámbito del ordenamiento jurídico privado que escape del influjo de los derechos fundamentales". La eficacia de los derechos fundamentales entre particulares, Bogotá, Universidad Externado de Colombia, 2000, p. 208. 
obligados a observar los derechos fundamentales fueran los poderes públicos, dejando a los entes privados en libertad para atropellarlos.

Con relación a América Latina, son catorce las constituciones que de manera implícita o explícita admiten la procedencia de acciones en contra de particulares con motivo de la violación de derechos fundamentales. Se trata, como resulta evidente, de una corriente dominante en el ámbito latinoamericano. Además, las instancias jurisdiccionales del sistema interamericano de derechos humanos también acogieron ya el principio de que los particulares pueden ser responsables de la violación de esos derechos; posición que por lo demás comparten con los órganos equivalentes de la Unión Europea.

Quedan abiertas varias incógnitas con relación a México. Es evidente el carácter restrictivo, en cuanto al concepto de autoridad responsable, del artículo 103 constitucional. Ahora bien, ante la doble circunstancia de morosidad legislativa y de apremio social en cuanto a la protección de los derechos fundamentales, ¿cabría considerar que la falta de defensa de los derechos fundamentales por parte de particulares es imputable, en último término, a los órganos del poder? Pensando así, ¿serían aplicables en México las ricas experiencias jurisprudenciales extranjeras? Estoy convencido de que sí es posible; de que la naturaleza de la Suprema Corte le permite ampliar razonablemente los medios de defensa de los justiciables, e integrar, mediante una interpretación acorde con los principios del orden constitucional, una laguna que hace vulnerables los derechos fundamentales de los mexicanos.

De tiempo atrás se ha entendido que las disposiciones legales de jerarquía inferior a la Constitución (entre las que se encuentran los tratados internacionales), no pueden restringir pero sí ampliar los derechos fundamentales contenidos en la norma suprema. Si esto es así por lo que atañe a los derechos, sería incongruente que no ocurriera otro tanto en lo concernido con sus garantías. ¿Cómo podría explicarse la expansión de los derechos sin su correspondiente garantía? Si esto sucediera, si el sistema 
consintiera la existencia de derechos sin garantía, sólo nominalmente podría hablarse de Estado constitucional; se trataría de una apariencia. La esencia de los derechos fundamentales no está en su enunciado sino en su defensa efectiva. La positividad de los derechos reside en su aplicabilidad.

La naturaleza jurídica de la Constitución hace que sus normas sean aplicables. En el caso de los derechos fundamentales debe entenderse que lo son, sólo en tanto que se puedan ejercer en todo tiempo, en todo lugar y ante todas las personas, con las salvedades que el propio ordenamiento adopte para los casos de excepción.

Desde luego, la vía más directa para alcanzar este objetivo sería la reforma de la Constitución en los términos que ha propuesto la Suprema Corte de Justicia de la Nación. Si la decisión legislativa sigue demorando, nada impide que la Corte adopte una interpretación análoga a la de otros sistemas, conforme a la cual, sin que se modifique el concepto de autoridad responsable del artículo 103 constitucional, se concluya que es en virtud de las diferentes omisiones del Estado que se violan los derechos fundamentales por parte de otros particulares.

Hay un aspecto que no debe pasar inadvertido: la ampliación de la jurisdicción de los tribunales para ocuparse de las violaciones de los derechos fundamentales por particulares, implica una revisión de la doctrina de la separación del poderes, que se basa en la relación de pesos y contrapesos entre los órganos del poder. La separación de poderes ha sido un constructo básico para el desarrollo del constitucionalismo moderno y contemporáneo, pero en la medida en que han aparecido agentes dotados de poder económico y político, que no podían ser previstos por la doctrina del siglo XVIII, es comprensible que se tengan que dar ajustes conceptuales razonables.

La doctrina de la separación de poderes fue una respuesta inteligente al absolutismo. Si bien la separación de poderes fue concebida como un mecanismo para atenuar e incluso evitar los excesos en el ejercicio del poder, y para garantizar así un espacio de seguridad para las libertades, 
paulatinamente fue siendo utilizada por los sistemas autoritarios para eludir la expansión de las funciones de control de los congresos y de los tribunales. Cualquier supuesta ingerencia de estos órganos en la actividad del gobierno, podía ser considerada como una desviación del principio de separación de poderes. Por eso se registran numerosos casos de sistemas autoritarios amparados en una rígida interpretación de la separación de poderes.

Los tribunales constitucionales han obligado a innovar la base conceptual del Estado constitucional, y la paulatina ampliación de los efectos horizontales de los derechos fundamentales, con el implícito reconocimiento de que los particulares también disponen de un poder real suficiente para afectar esos derechos, contribuye a dilatar la esfera de competencias del único órgano del Estado que puede ofrecer soluciones satisfactorias. En tanto que los partidos políticos están directamente involucrados en la integración de los gobiernos, y en la medida en que la lucha electoral acentúa la naturaleza agonista del poder, es comprensible que las funciones arbitrales de los tribunales tiendan a aumentar.

El Estado constitucional implica una cultura democrática conforme a la cual los miembros de la sociedad participen en el juego electoral sin poner en riesgo sus derechos de libertad y de autonomía. Esto sólo se consigue merced al fortalecimiento de los órganos judiciales; la acción objetiva, imparcial y efectiva de los tribunales genera un entorno de seguridad y confianza que hace posible absorber las tensiones propias de los sistemas políticos altamente competitivos.

Por eso los criterios jurisprudenciales guardan estrecha relación con la cultura. El acceso a la justicia tiene una doble implicación: por un lado requiere de elementos instrumentales, tales como jueces y abogados, y por otro supone una relación social de confianza en las instituciones. Los solos instrumentos no bastan, si no existe la percepción generalizada de su utilidad, y la confianza, sin los elementos para alcanzar resultados prácticos, tiende a decrecer. Ambos factores deben darse de manera sincrónica. Esto es lo 
que se pone de manifiesto en el caso de la protección de los derechos fundamentales frente a particulares.

Los jueces son sensibles a los cambios que se producen en la sociedad. Las solicitaciones de justicia que se les dirigen corresponden a la fluidez de las relaciones sociales. La vida colectiva es a tal punto proteica, que requiere de unas respuestas flexibles y oportunas que sólo los jueces pueden ofrecer. El legislador, a veces, anticipa algunas soluciones, pero por lo general actúa para resolver asuntos que ya se generalizaron. Los problemas y las soluciones germinales se advierten a través de la jurisprudencia. En un Estado constitucional las funciones legiferante y jurisdiccional se imbrican, no en el sentido de invadirse sino en el de complementarse: al legislador le toca dotar de atribuciones amplias al juez, y estar atento a lo que éste resuelve, para ir innovando las instituciones de justicia; al juez le concierne procesar las expresiones del cambio social, que le llegan como casos a resolver, y que se producen de manera lenta pero normalmente clara. Cuando los titulares de las instituciones saben desempeñar este papel constructivo, la separación de poderes adquiere una nueva dimensión. 